\title{
Human Capital Information Systems: An Introduction
}

\author{
Hayel T. Ababneh ${ }^{1} \&$ Fayiz D. Shrafat ${ }^{2}$ \\ ${ }^{1}$ Al Al-Bayt University, Business Department, Jordan \\ ${ }^{2}$ Department of Management, The Hashemite University, Zarqa, Jordan \\ Correspondence: Hayel T. Ababneh, Al Al-Bayt University, Business Department, Jordan. E-mail: \\ hayelababneh@aabu.edu.jo
}

Received: May 22, 2014

Accepted: August 11, 2014

Online Published: August 22, 2014

doi:10.5539/ijbm.v9n9p193

URL: http://dx.doi.org/10.5539/ijbm.v9n9p193

\begin{abstract}
This article seeks to look into the needs of users of Human Resource Information Systems (HRIS) in Jordan. Its primary purpose to analyse the existing and future functionality that will help HRIS to improve the performance of the HR function and the value of human capital. This paper takes the opportunity to improve the understanding of the future of HRIS and its impact on transforming the approach to HRM and introduces a new concept: Human Capital Information Systems (HCIS). HCIS is potentially a new paradigm for HRIS development which indicates a shift in thinking about its future potential. Personal interviews were used to collect data from HR professionals and managers in the telecommunications companies of Jordan. Through considering the influence of culture, religion, human and other contextual factors on users' attitudes towards the use of HRIS, newer functionalities are expected to facilitate the further development of new more employee-centred systems.
\end{abstract}

Keywords: Human Resource Management, HRIS, HCIS

\section{Introduction}

Before the 1960s computer systems had been used for a very limited purpose in human resource management and were used only for accomplishing administrative tasks such as monitoring employee records and payroll activities (DeSanctis, 1986). After this era, in the 1970s, most large USA organisations developed some form of personnel data system (DeSanctis, 1986) that could provide managers with information relevant to HR needs (Hennessey Jr, 1979). After a decade the percentage of organisations that had HRIS increased to $40 \%$ (Richards-Carpenter, 1982) and it has now become a major management information systems sub-function in most large organisations (Chien and Chen, 2008).

The level of use of HRIS is determined on the basis of the complexity of the tools being used. As discussed by Evans et al., (2006), the use of HRIS passes through three generations. The first generation of HRIS involves an initial level of use which is mainly transactional such as payroll processing and providing the employees with training information. The second generation of HRIS allows the undertaking of HR practices that were not feasible previously. It involves moderate improvements in the way HRM functions are practiced such as improvements in performance appraisal and recruitment. The third generation of HRIS enables HR to perform some practices that could not be performed before such as regular measurement of the effort that people put into their work.

Several surveys indicate the continually increasing number of organisations adopting HRIS and the intense dependence on its applications within the organisations. The use of HRIS has increased significantly in the past few years. Now HRIS have a wide range of uses and are considered to be vital in collecting job information, recruitment, employee selection, training and performance management (Chapman and Webster, 2003).

Recently HRIS has been used to support decision-making as a way to gain competitive advantages (Broderick and Boudreau, 1992) while Martinsons, (1994) shows that HRIS was used mainly to carry out routine tasks like filing and recording. Similarly, in UK SME's (Ball, 2001) reported similar results in which HRIS is still used for operational rather than strategic purposes. More recent research shows heavy use of HRIS and more focus on it for strategic decision making (Hussain et al., 2007).

As the result of the complexity of the competitive environment many organisations are seeking ways to improve 
information management by utilising IT in all of their functions. They realise that to improve organisation performance through people they must turn to HRIS (Haines and Petit, 1997). Currently HRIS is not limited to administrative purposes but it is also used also for strategic and decision making purposes (Broderick and Boudreau, 1992, Kovach and Cathcart, 1999). Initially it could be clearly seen that systems were used in HRM to support transaction processing and to maintain management control. Currently new information technology is used to improve decision making and support competitiveness. Through this brief outline of the evolution of HRIS it can be noted how HRIS is moving away from an operational device toward a fully strategic and information analysis tool.

\section{Technological Transition}

The term "transition" typically refers to the process of changing or a period of change from one state or condition to another. It could be defined also as the movement, passage or change from one position, form, state, style, stage or subject to another. In this research transition is defined as the change from the current status to a future and/or projected state of use by adding or removing some functionality.

Different socio-technical theories were highlighted to explain how HRIS is being developed and/or shaped. According to these perspectives the appearance of technology is determined by its contextual settings. Socio-technical perspectives gave a richer understanding of the use of technology. Similarly HRIS transition is also subject to the same notions that have been mentioned previously and thus HRIS transition needs to be understood on the basis of socio-technical theories. Socio-technical theories suppose that the performance of the existing and new system can be improved satisfactorily if social and technical perspectives are brought together (Clegg, 2000). Based on the perspectives of socio-technical theories (Cherns, 1987) has developed some principles to be followed in developing an IS. Afterward, Clegg, (2000) extended the work of Cherns by suggesting a more integrated set of criteria to be followed by system managers, users and designers within the organisation. Accordingly in transitioning a system some issues need to be considered; values and mindsets, the needs of the business, its users and their managers, contingent design, social shaping of design, simplicity in designing the new system, resources and support and political processes. To guarantee successful transition all these perspectives have to be taken into consideration before the decision to transform the existing HRIS.

In the study of Luna-Reyes et al., (2005) it is stated that IS transition is an emergent and dynamic process which can be characterised or driven by local adaptations. Following the view of socio-technical change they propose a framework which shows the dynamics of social and organisational factors that cause success and failure in the IS transition process. Drawing on "The Question Concerning Technology" (Heidegger, 1977) that is considered as the most influential work in the philosophy of technology, Ciborra contributes to our understanding of technology by analysing Information Infrastructure using the concept of "cultivation". Accordingly transition is an ongoing or continuous process which means an emergent approach has to be followed to understand the technological, social, and cultural factors influencing the transition process and in understanding the expectations, norms, and perceptions of different actors within specific organisational contexts (Jackson and Philip, 2005). In the light of the "tactics of cultivation" as suggested by Ciborra, (2004), this work explores the contextual factors that may affect the use and development of a new technology and HRIS specifically.

The beginnings of understanding the traditional ways of managing technological change start with the work of Lewin, (1952) in his three-stage change model of "unfreezing", "change" and "refreezing" (Kwon and Zmud, 1987). However in today's more unstable, flexible and vague organisational and environmental conditions such traditional models - in which predefined steps are located in advance - are becoming less appropriate due to unexpected events that can occur from time to time. An alternative model of managing technological change suggested by Orlikowski and Hoffman, (1997) has the ability to reflect the emergent, turbulent, uncertain and changeable features of contemporary organisations and technologies.

Bussler and Davis, (2002) argue that in future, and due to the increasing trend in globalisation, there will be an increasing need for systems with the capability to translate into multiple languages. Another future vision for HR is to launch technologies with the ability to cultivate knowledge management by storing best practices in their HR knowledgebase within reach of all employees. Many forces such as globalisation, diversity, complexity of modern organisations and IT have changed the scope of organisations (Shrivastava and Shaw, 2003). These forces drive change that requires more agility, flexibility and quick reaction. To compete effectively firms need to focus on more strategic issues like learning and importing knowledge, reacting quickly to emergent opportunities and delivering better services to customers (Snell et al., 2002). These forces compel HR to transform from being an administrative function into a more strategically oriented function by being involved in the planning, development and execution of business strategies (Alvares, 1997). A survey conducted by CIPD, 
(2003) revealed that $33 \%$ of HR practitioners in the UK are performing the role of strategic partners while $56 \%$ are looking for this role in the future. For these reasons organisations have become equipped with more effective tools to compete in a changing and highly competitive environment and to gain the required competitive advantage by investing in the means for enhanced management of human capital. Consequently, to achieve the desired long term and future prospects, managers should be aware of the complexities of the surrounding social and cultural factors together with the technical issues.

Based on the above discussion, it could be argued that technology is continuously evolving and the role of technology in today's HRM is also in continuous change. Additionally technology is much needed for successful business. In the attempt to elevate the performance of HRM, technology is presented as a way of achieving more effective and productive results. The role technology plays in HRM shifts from being simply operational to involving the realisation of strategic objectives and accomplishment of competitive advantage.

\section{Methodology}

Due to the exploratory nature of this research which aims to analyse the relationship between HRIS and HRM, predict its future potential, understand the contextual factors, and to recommend changes (Scapens, 1990), it follows the IS interpretive case study strategy (Myers, 2008, Walsham, 1995). A further rationale for the choice is to keep away the restraints of mechanistic procedure, to increases the likelihood of generating novel theory, and to gather rich data on the use of HRIS and its broader cultural, organisational and social context (Myers, 2008, Orlikowski and Baroudi, 1991).

Informants were drawn from two telecommunication companies in Jordan. Two non-probability sampling methods, purposive and convenience sampling were adopted in this research (Bryman, 2001). In order to attain a significant insight into the subject under study, they were selected according to relevancy, availability to participate in the study, and on the basis of experience and knowledge, (Morse, 1994). The targeted respondents are HR professionals, top managers and line employees. 22 interviews were conducted in two case studies as shown in Table 1. The interviews were conducted with some volunteers who showed their acceptance of participation. These respondents were asked to nominate other knowledgeable respondents who would provide a useful insight into the use of HRIS in the company. The researcher stopped interviews when the degree of theoretical "sufficiency" was achieved in order to build a convincing theory (Andrade, 2009). This process continued by asking every single respondent to nominate another until no added value was obtained from further data.

Table 1. Categories and numbers of interviewees

\begin{tabular}{lll}
\hline Category of Interviewees & $\begin{array}{l}\text { Case study } 2 \\
\text { Alpha }\end{array}$ & $\begin{array}{l}\text { Case Study } 2 \\
\text { Beta }\end{array}$ \\
\hline Senior Managers & 2 & 2 \\
HR Professionals & 6 & 7 \\
Employees & 2 & 3 \\
Total & $\mathbf{1 0}$ & $\mathbf{1 2}$ \\
\hline
\end{tabular}

\section{Results}

Based on the knowledge the researcher acquired during the field study to collect data for this research, it was shown that the respondents have a bounded outlook toward the future of HRIS. They expressed their opinions about the current HRIS and contented themselves by saying that this system is not enough. The responses collected could be explained by the need to use more developed systems with high level functionalities, or another paradigm of HRIS which is derived from the current HRIS to meet high level of requirements, and satisfy the needs of both organisations and users alike.

The majority of respondents were highly confident about the capabilities of HRIS in the future. They supported the results of Martin et al., (2008) in their study, which describes many positive transformational outcomes when HRIS has been updated. Different responses showed a high degree of confidence in the future of HRIS as they perceive how helpful it is in improving the performance of HR professionals and different users through the organisation. Although the existing HRIS is mainly used for limited purposes, respondents clearly reflected a high level of satisfaction. As a result, they are looking forward to acquiring more functionality and to customising the existing HRIS to be consistent with their future aspirations. 
The external conditions surrounding JMTCs is characterised by a high degree of fluctuation and uncertainty in terms of technological developments, competition and economic conditions; JMTCs are struggling to cope with these environmental changes. Accordingly, they are receptive to changing approaches that enable internal conditions to be consistent with external conditions. Additionally they are trying to catch the opportunities and to avoid the dilemmas that may appear.

Both JMTCs are working in the same conditions, facing the same challenges; they are both affiliates of global companies, working in the same sector serving typical customers, having the same governmental regulations imposed on them and struggle to recruit workers from the same pool. These typical features impose high pressure on both JMTCs to compete strongly. They are aware of the importance of their human resources and the need to allocate more attention to them by providing every kind of support to sustain growth and development. People are considered the main asset in the JMTCs; they are given the ultimate importance and priority.

Many respondents believe in HRIS as a tool that can be improved to deliver further outcomes which will positively reflect the value of human resources. Some flaws in the existing HRIS mean that this improvement is still in the future, beside the need to acquire some functionality already provided by HRIS vendors, there is also some functionality which has not been developed yet. Having reviewed the functionalities provided by different HRIS vendors such as SAP, Oracle and others, it is noted that the majority of functions are automated to improve the organisational performance specifically of the HR department; however, to raise the significance of human resources other functionalities are necessary. Because of the growing interest in the human element in the two JMTCs, senior managers and HR professionals raised many issues that illustrated their desire to have more advanced functionalities embedded in HRIS. Furthermore line employees have added that some shortcomings exist in the current HRIS which undermine their importance, on the other hand, updating it could help to underline the value of human resource and its transformation into human capital. This transformation means changing the role of employees from performers achieving certain tasks into knowledgeable persons, intellectual asset and experts achieving more knowledge (Argyris, 1993).

Many suggestions for the future HRIS were revealed by different respondents in both JMTCs. They suggested new functions to be performed by the use of HRIS such as developing existing and future talent, individualised learning development, managing knowledge exchange and developing a distributed communication database. The suggestions that emerged from different responses in both JMTCs indicate that they consider people the most important asset that must be nurtured, emphasised and paid the highest attention. These suggestions for the future of HRIS are a reflection of the organisational vision to satisfy employees' needs. Responses collected from senior managers showed a clear relationship between employee satisfaction and meeting customers' needs. To satisfy customers' needs, employees should be treated deferentially and provided with all requirements for progress and development.

To support the data gathered from the two case studies, the HR modules offered by two popular vendors of HRIS solutions were evaluated to scrutinise how demand and supply of HR solutions diverge.

\subsection{Analytical Look at HR Solutions Developed By Oracle and SAP}

In reviewing the solutions provided by the most popular vendors of HR solutions; Systems and Application Products (SAP) and Oak Ridge Automatic Computer Logical Engine (ORACLE), it is clear that people are still considered a human resource. The two companies are still providing HR solutions that maximise the ability of the organisation to exploit employees' skills and abilities when needed. Consequently, the main purpose of the existing HRIS is to improve the performance of organisations by better management of people issues. On the other side, human capital is undervalued and paid less attention by organisations. Vendors of HRIS respond to the requirements of business organisations looking to use HRIS. It may be noted that organisations claim to be interested in human capital but in reality they only need some HR modules which enable them in managing human resource. The functions listed in Table 2 demonstrate the main HR functions that are automated by ORACLE and SAP. 
Table 2. Main human resources solutions provided by ORACLE and SAP

\begin{tabular}{ll}
\hline ORACLE HR Solutions & SAP HR Solutions \\
\hline Global Human Resources & Core HR and Payroll \\
Workforce Management & Benefits Enrolment \\
Payroll Management & Talent Management \\
Labour Rules and Monitoring & Workforce Planning and Analytics \\
Workforce Service Delivery & Time and Attendance Management \\
Talent Management & Business Suite Applications \\
\hline
\end{tabular}

Source: compiled from www.sap.com and www.oracle.com (2014).

Many organisations believe that investment in human capital could be the investment offering greatest returns. Human capital is a combination of skills, understanding, knowledge, and experience. Therefore, the best investment in human capital could be made by providing opportunities for learning, future development, sharing knowledge, managing talents, improving relations and other recognition programmes. Given that people are the richest source of competitive advantage, then advantage could be achieved by investment in human capital through providing more functionality in HRIS that emphasises the value of people in organisations. It could be argued that the existing functionalities provided by HRIS vendors are not adequate for satisfying the goal of maximising the value of human capital.

Oracle provides what is called learning management, but investigating this module in depth shows that it is no more than training. In detail the learning module is able to deliver and track training participation, to keep track of training needs and to roll out training programmes. However, learning entails focusing on learners and their needs, rather than on organisational needs. According to Bee and Bee (1998), training is differentiated from learning by its consciousness and the planned process. Learning is something people do for themselves with some assistance from the organisation, that way they remain accountable for their achievement. Thus, learning is a voluntary effort by a person willing and self motivated to gain knowledge in a specific area. This willingness is reinforced by the provision of assistance from the organisation.

Unlike training which is focused on a specific job, learning is associated with people nominated for promotion or assigned to advanced roles. Learning is also needed to improve the potential of employees at different levels. Therefore employee learning can only be evaluated once they move on to their proposed jobs. However, trainees can be evaluated immediately once they return back to their current jobs. Development is associated with improving personal capabilities which are not related to current or future jobs. This means that learning is guiding people to acquire new horizons or viewpoints. It assists employees to invent new ideas to improve new processes, to create new products and services and to establish a new competitive advantage (Mayo, 2004). Consequently, these two practices; learning and development can be considered the antecedents of managing knowledge exchange.

One of the interesting findings in this research is that some respondents showed a high degree of interest in their learning being guided through HRIS. The need for this continuous learning approach is a consequence of rapidly changing circumstances. Managers in the JMTCs need to enable employees to adapt their capabilities to cope with possible changes. All employees in the different levels are expected to be included in learning schemes embedded in the prospected HCIS. Indeed, these learning approaches will increase the level of employees' understanding of different topics that may maximise their performance indirectly in their current and future jobs.

Additionally "Oracle Talent Management" entails assessing employees to ensure the right training and development opportunities are provided. Therefore it evaluates the competencies of employees against the required competencies for a specific role. Theoretically talent management is a systematic way of acquiring, recognising, developing, retaining and exploiting those individuals' competencies which are of particular significance to an organisation (Kennedy, 2006). Talent management steps beyond comparing the expected and possessed competencies of individuals to reach employees in transition by developing, managing, challenging, promoting, motivating and more. The purpose of talent management is to prepare for the future.

It is clearly apparent that suggested new functionalities are misunderstood, overlooked or misapplied by the vendors of HRIS. The incomplete conceptualisation of these aspects leads to the inability to cope with organisational visions about transforming human resource into human capital. Such aspects are critical to contemporary organisations that view employees as their main competitive advantage.

Consequently, there is a gap between theoretical propositions and the actual practice of using HRIS. The 
elements of "Managing Knowledge Exchange" and "Developing Distributed Communication Database" joined with "Talent Recognition and Development" and "Individualised Learning Development" assist the workforce to be aware of their value in the organisation. Automating these activities through an integrated system helps the organisation to reap the promising opportunities they offer. When ability and willingness work together, many possibilities may be opened up. If an individual has the willingness to learn, to share his/her knowledge, to socialise, then HCIS can provide the ability that helps them to achieve their objectives.

\subsection{The Need for HCIS}

There is much research about future trends in HRIS (Kavanagh et al., 2011). These trends include applying new functionality to enhance the strategic level of HR which emphasises the organisational side of HRIS and neglects the needs of people inside the organisation. The traditional approach to formulating current and future functionality considers all HRIS users as function utilising agents who require certain tasks to be completed in order to fulfil their jobs. This functional approach, though quite practical in generating numerous functional specifications, does not consider such factors influencing users' attitudes towards HRIS use such as culture, religion and the human side of the organisation. Therefore, the concept of Human Capital Information System is suggested in this section. The change of name from HRIS to HCIS is rather symbolic and emphasises that the new system needs to be user-centred not only in its functionality but should consider other contextual factors.

Although some business organisations have changed their attitude towards human resources they still use the existing HRIS, which is unable to fulfil the requirements and aspirations of people whom are supposed to be considered the most important element in the organisation. Therefore the current use of HRIS does not recognise people as human capital.

It is commonly acknowledged that the value of an organisation is a blend of physical assets such as buildings, land and equipment with intangible assets such as knowledge, reputation, and of course, people (Barney and Wright, 1997). Human resources are the most valuable asset in organisation and should be invested in for the organisation to thrive, to achieve more of its desired outcomes and to continue to survive against competition (Wright et al., 1994, Hatch and Dyer, 2004, Barney, 1991). Therefore business organisations have to use a system that meets their changed concerns and fulfils the requirements of changing business strategies especially under the circumstances of aggressive competition. This new system has to include capabilities that step beyond offering transactional and transformational outcomes towards enhancing the value of people.

The value of employees can be improved in two ways: 1) paying more attention to the employees, making them feel more appreciated and honoured to the point that they recognise themselves as the key element in their organisation and distinct from those in other competing organisations, and 2) improving the material and cognitive abilities of the employees to exceed the abilities and skills of employees in other organisations. These two ways will encourage the employees to develop a sense of dignity and honour. The main purpose of HCIS is to create and to improve such a sense within employees by focusing on the mental and moral aspects of employees.

In this regard, the metaphor of the human body could be used to explain the difference between HRIS and HCIS. The existing HRIS is used mainly for achieving organisational results such as productivity, efficiency, minimising costs, etc. which means focusing on the physical side of organisation. HRIS is the muscles of the organisation's body which facilitate movement and effective working. On the other hand, HCIS can be portrayed as the brain of the organisation that enables smarter working by focusing on the mental side of the organisation. As a result HCIS is about more than just technical functionality but extends to serve the human side of the organisation.

Innovative and advanced HCIS that goes beyond transactional and transformational tasks is concerned with people as human capital not just human resource, which means giving more attention to the individuals as the most valuable asset of the organisation. HRIS can be transformed into HCIS; a more sophisticated tool that deals with and treats people as a precious asset in the organisation giving more attention to people and caring about their interests, intentions and needs in order to improve their professional aspirations. HCIS can enable individuals to be more appreciated and valued if the existing HRIS is enabled with other capabilities intended to serve people.

Responses collected from different sources in the two JMTCs indicated a strong need for four functionalities to be included in the proposed HCIS (Section 5.9). These functionalities are talent recognition and development, individualised learning development, managing knowledge sharing, and developing a distributed communication database. The most prominent features of these functionalities are the overlap and the high dependency on each other. 


\subsection{Talent Recognition and Development}

According to (Kavanagh et al., 2011), talent management functionality in HRIS has an emphasis on talent identification, setting objectives to measure performance and other initiatives to support the talent management function within a company. This rather mechanical function of identifying talent on the basis of quantifiable performance is quite limited even in identifying talented employees in jobs which cannot be quantified and it does not consider relational and other factors affecting performance at work. Therefore, the talent management function can be expanded by placing more emphasis on talent recognition and development that requires a more holistic approach, considering the overall job environment, often referred to as organisational context (Ein-Dor and Segev, 1978, Avgerou, 2001).

Using HCIS to manage talent can help to improve business planning and decision making significantly. However, it requires some modules to be used in advance such as performance appraisal, and training and development. These modules are already used by the two JMTCs so they are keen to automate the process of managing talent, which is already an existing HR practice. By measuring and analysing reports extracted from these two modules valuable data can be produced to refine the process of attracting and retaining talented people which is helpful for planning for the future. As long as those talented people have the abilities, skills and knowledge; organisations need to identify those talented people for better practice of succession planning and knowledge management.

HCIS can help organisations to discover talented people from both internal and external sources. When they have been recognised, HCIS can also help to cultivate their abilities using training and learning programmes. Consequently, HCIS has the ability to improve the way in which human resources are managed. Similarly, as they consider employees in their organisations as the most significant asset, they are obliged to introduce a specialised talent management programme into their HR practices which can be automated to achieve better results for those employees. Compensation planning is an enabling factor for managing talent well because it helps organisations to retain talent by ensuring they get suitable rewards. However, compensation planning is insufficient and needs to be enhanced with other automated functions.

To retain talented employees HCIS can help in providing them with opportunities for career progression within the organisation. The compensation and reward functionality should be used to align pay with the added value created by talented employees. Additionally favourable working conditions will help in retaining the skills and knowledge of such people. Looking for the able employees who have the ability to create value for the business is the essence of this functionality through selective recruitment. However, the functionality of talent recognition and development should be tied with other supported functionalities such as recruitment, rewarding, performance appraisal, and training.

\subsection{Individualised Learning Development}

The traditional approach to including training and development in HRIS is based on availability of internal and external training modules providing push style training courses for users to enhance employees' experience. This function can be transformed by automating employee learning development which aims to provide discretionary learning activities. Through these learning activities improvements in employees' intellectual abilities can be achieved, the organisation can create an atmosphere of autonomy so that individuals are able to develop their talents and refine their own skills. Investment in learning by organisations is essential in order to maintain existing human capital and retain it. Thus, individuals become more committed to their organisations as they are more valued and appreciated. By offering individualised learning development through HCIS, people will gain the impression that the focus of management is on improving their competencies which are the scarce resources available in the organisation. Additionally, automating the learning function enhances individuals' attitudes towards themselves as a permanent rather than contingent resource. As a consequence, viewing the existing HRIS as a tool for managing knowledge and learning along with managing conventional HR practices will transform the existing HRIS into HCIS. Once organisations recruit the most competent individuals and manage their implicit knowledge by development and learning they will possess a competitive advantage which cannot be imitated and they will become the most powerful competitor (Ofek and Sarvary, 2001, Argote and Ingram, 2000, Hatch and Dyer, 2004).

Increasing the value of employees is also a result of creating a climate of respect for employees by implanting advanced HR practices. For effective results this functionality, namely individualised learning development, is expected to educate employees and to provide them with the required skills for problem solving and even creating opportunities and thus, HCIS transforms every employee into a manager.

The most successful companies are those that manage human capital in the most effective and efficient way by 
investing in their individuals, encouraging workers to invest in themselves, providing a good learning environment (Becker (2002), cited in Gamage, 2007). Bringing learning into HCIS enables employees and managers at all levels to improve their level of knowledge. Thus, individuals can learn whenever knowledge is available that may assist with acquiring and sharing knowledge between individuals. Learning is not restricted to a certain category of employees but may extend to reach managers. Investments in formal or informal education increase an individual's level of productivity and thus improve their earning potential (Gattiker, 1995). They can be educated and learn about various managerial issues such as leadership approaches and managerial skills. By pursuing individualised learning, employees become more willing to fulfil their potential, which can in turn help organisations to achieve their desired goals and also helps individuals to be more satisfied with their working lives. Additionally, organising and monitoring learning activities through HCIS can enhance the performance of organisations. On the other hand, embedding learning inside HCIS can also create an impression that improving individuals' knowledge is the main focus of management. Learning is not limited to offering job related courses, but can also be used to deliver information which could be of benefit to employees in their personal lives.

The essence of this functionality is to foster cognitive skills rather than non-cognitive skills already enhanced by the use of the existing training functionality in the existing HRIS. These kind of skills are equally important, if not more important, in a modern economy. Learning development is especially important in a knowledge-based economy, where innovative new ideas are greatly valued to meet the challenges of this new economy. It is thus crucial to have highly educated human capital to provide a competitive edge. This is especially so in countries such as Jordan which depend mainly on manpower.

\subsection{Managing Knowledge Exchange}

To facilitate knowledge exchange organisations need some tools to manage, nurture and retain human capital. In order to retain the required knowledge, people from all departments and even affiliates should be connected with each other by means enabling knowledge exchange. HCIS can be in help by facilitating these connections through the use of its learning and training functionality. This functionality should ensure a mix of a subject-centred knowledge database with interactive capabilities similar to those provided by social media. This will enable knowledge exchange to be a self-sustaining function and would minimise the burden of topping up the knowledge base.

Once talented people are recruited and/or identified, organisations have to manage and utilise the skills, abilities, and knowledge they possess. These competencies should be managed carefully to improve organisational performance. Through HCIS, this wealth of human competencies and knowledge are to be shared with others to obtain better results. HCIS which links all departments and affiliates can help by converting embedded knowledge into observable and applied knowledge in its different types; service, customer and managerial. Beside the previous functionality, employees can learn from the experience and knowledge of each other within the organisation. The knowledge gained by employees has to be shared between employees by using a suitable channel that gathers all employees into one place even if virtually.

HCIS can enhance the sharing of knowledge within the workplace by enabling the posting of knowledge making it available to other parties within the organisation. In spite of the disparity between the source and destination of this knowledge, individuals, groups and even affiliate of the main company can obtain that knowledge. This knowledge thus can be transferred within different locations to every interested person. Through HCIS, employees can share their knowledge by connecting them to work collaboratively in a particular issue that needs to be solved or to discuss new opportunities such as developing a new project.

According to (Alavi and Leidner, 2001), there are three main applications of IT to manage knowledge exchange: (1) The internal benchmarking by transferring and sharing internal best practices. (2) The creation of corporate knowledge directories by mapping internal expertise which helps to avoid reproducing the same mistakes, and to enable accessing the organisational best knowledge. (3) The creation of knowledge networks by bringing people together virtually to exchange their collective knowledge in different specialty areas. Consequently, HCIS could help in exchanging the knowledge and expertise of all people in the entire organisation. Through one integrated system, employees in different levels can access all necessary information in their current or future jobs.

Managing knowledge depends mainly on people; therefore, when they are recruited, trained, evaluated and rewarded, then creating, sharing and using knowledge becomes more feasible. Recruiting competent individuals with particular skills and abilities is essential to gaining knowledge from diverse sources. Similarly, talented and knowledgeable people must be kept up to date with advances in their profession by use of the training and education functions. Furthermore, fair reward based on evaluation of performance both encourages individuals to be more committed to their organisations and more willing to share their knowledge for use within the 
organisation.

Acquiring and sharing knowledge requires a significant degree of commitment in order to work. When talented people are committed enough, they become more willing to gain and distribute knowledge. The role of HCIS is clear in that it assists in generating commitment to the organisation by simplifying employees' work and supporting an organisational climate of fairness and standardisation in recruiting, training, evaluating and reward. Afterwards, once knowledge is available to be shared, HCIS can simply transfer knowledge wherever is located to wherever it is needed.

Acquiring and sharing knowledge needs a sense of commitment and belonging, then HCIS can be used to produce many positive organisational and individual outcomes. A sense of commitment and belonging can be created if human capital needs are met. People need to be rewarded fairly and they also need to feel important and needed. HCIS has the ability to track employees' performance which can then be rewarded according to equal, fair and transparent standards which are applied to all individuals without discrimination. Furthermore, HCIS can help to bolster the self-image of talented employees as being valued by the organisation. Consequently, individuals become more committed and willing to transfer their knowledge into organisational knowledge.

\subsection{Developing a Distributed Communication Database}

Human capital is not composed of alienated members but it is a collective group bonded together by formal and informal connections. Human capital is more likely to be a group of empowered employees who are working cooperatively to achieve the interests of the organisation. HCIS can help organisations by paving the way for improving personal connections between different parties within the organisation. The usual communication capability provided by HRIS is centred on the idea of a portal or a place within the company's intranet where all news is propagated. This approach makes this portal a repository of information rather than a tool which would enable lateral communications and hence help to improve relationships between managers and subordinates, within and between different work groups, branches, department, units and functions within organisations. Also, improving relations between employees may contribute to minimising and even eliminating job stress.

Additionally conflict resolution can be achieved through HCIS by presenting a specific emerging issue to the public within the boundaries of the organisations and receiving constructive feedback from people willing and interesting in resolving the issue. Conflicts can arise between individuals or groups, dedicating a specific area within HCIS can allow people from different branches, divisions, departments within the organisation to cooperate in resolving these issues. Consequently, they become more empowered to share ideas which can be employed in practice. Through these issues and subsequent thoughts, employees are more likely to learn intuitively.

In addition to preventing and resolving problems, strengthening relationships between employees and their organisations can also bring opportunities. This functionality could be added by HRIS providers in which employees at many levels can pull information, feedback, comments and suggestions from a range of interested people within the organisation. All these suggestions can be saved in a database to be used for different purposes. This functionality will enable the managers to analyse data to make appropriate decisions or actions. Different groups can also exploit this feature to solve their own problems or to collect constructive ideas which may help in creating new business opportunities.

A communication database can also be used for employee surveys which consider employees' needs and interests when changes are made. Some kinds of surveys can be conducted throughout the organisation to compare the turnover rates between its different parts and to show the particular issues related to turnover. HCIS-enabled-surveys can also provide the organisation with a useful insight about the intentions of employees around continuing to work for the organisation. This kind of formal or informal communication through conducting such surveys will provide a positive opportunity to open discussions regarding important issues for both the business and employees. On the organisation level, keeping all the collected data in one database can be helpful for the analysis of changing issues or sorting out issues which have emerged. Additionally, such communication will be helpful in gaining employees' commitment and retaining talent.

As suggested by some respondents, HCIS can be used for the purpose of encouraging employee participation by allocating a space for employees to suggest new ideas to solve problems or bring benefits. Allowing individuals to participate in solving problems gives them a sense that their organisation cares about them and respects their suggestions and opinions; therefore, self value can also be improved. Moreover, the resolution of employees' grievances can be tackled through HCIS. All individuals have the right to criticise management or to air their grievances. Consequently HCIS has the potential to improve the power of individuals as they become considerably more involved in change and re-shaping their organisations. 
Once these aspects are embedded into the existing HRIS, employees will be transformed into human capital instead of just human resource. Consequently, HRIS have to be changed into HCIS, which considers people as the most valuable and crucial asset for acquiring competitive advantage. Therefore, it could be argued that the projected HCIS will assist both organisations and individuals to achieve self development and growth.

As a result, if the organisation intends to focus on human capital adding the capabilities mentioned above into future versions of HRIS is a necessity. The people focus is important in order to elevate the abilities of the organisation's human capital and to manage them as a core element in the organisation. Additionally, these practices, supported by a computer based system, will help organisations to create competitive advantage by retaining valuable and inimitable human capital. Finally, it could be argued that through HCIS, human capital will be well recruited, retained, equipped with knowledge and expertise, empowered, and involved in decision making and solving problems.

\section{Conclusion}

It was clearly shown that the potential of HRIS is determined by the established business vision and long term strategies. It was found that employees in JMTCs enjoy substantial attention from their managers because of high competition within the telecommunication industry. JMTCs are competing to acquire and retain the most qualified people by providing them with all possible assistance at both job and personal levels. HR professionals in JMTCs showed a high need to develop the existing HRIS to include other functionalities that would improve the value of human capital within their organisation. An orientation towards people is a result of their inclination towards future investment in human capital to enhance their competitive position. As a result some functionality, which are not supplied by HRIS vendors, were indicated as being highly desirable in both JMTCs in order to contribute to increasing the value of human capital. Four types of additional functionality were suggested: talent recognition and development, individualised learning development, managing knowledge exchange, and developing a distributed communication database.

The overall outcome of this new paradigm within the existing HRIS may lead to achieving a distinct transformation in HRM practice and improvement in the value of human assets as employees are claimed to be and found to be the most valuable asset contributing to an influential competitive edge in JMTCs. Thus the current HRIS is no longer as helpful as it could be unless it is transformed into another paradigm which has new features. This new paradigm enables the creation of more value from human capital for the purposes of professional development and furthering organisational objectives. New functionality will update the current system into a more advanced system with content developed to meet the cognitive and relational needs of human capital. Adding the suggested new functionality may create an impression among employees that they are not only a means for achieving the goals of the organisation but are the most vital element in the organisation. Accordingly, this will reflect positively on employees' self-perception and sense of worth within the organisation. This way of drawing on the legacy of HRIS is conceived by (Ciborra, 2002) as a hospitality metaphor, implying that the hospitality and cultivation methods need to be followed in developing the existing Information Systems. This new paradigm suggested in this research is Human Capital Information System (HCIS) which is expected to advance the workforce from being just human resource into human capital.

\section{References}

Alavi, M., \& Leidner, D. E. (2001). Review: Knowledge management and knowledge management systems: Conceptual foundations and research issues. MIS quarterly, 107-136.

Alvares, K. M. (1997). The business of human resources. Human Resource Management, 36, 9-15.

Andrade, A. D. (2009). Interpretive research aiming at theory building: Adopting and adapting the case study design. The Qualitative Report, 14, 42-60.

Argote, L. \& Ingram, P. (2000). Knowledge transfer: A basis for competitive advantage in firms. Organizational Behavior and Human Decision Processes, 82, 150-169. http://dx.doi.org/10.1006/obhd.2000.2893

Argyris, C. (1993). Knowledge for action: A guide to overcoming barriers to organizational change. ERIC.

Avgerou, C. (2001). The significance of context in information systems and organizational change. Information Systems Journal, 11, 43-63. http://dx.doi.org/10.1046/j.1365-2575.2001.00095.x

Ball, K. S. (2001). The use of human resource information systems: a survey. Personnel Review, 30, 677-693. http://dx.doi.org/10.1108/EUM0000000005979.

Barney, J. (1991). Firm resources and sustained competitive advantage. Journal of management, 17, 99-120. http://dx.doi.org/10.1177/014920639101700108 
Barney, J. B., \& Wright, P. M. (1997). On becoming a strategic partner: The role of human resources in gaining competitive advantage.

Bee, F., \& Bee, R. (1998). Facilitation skills. Institute of Personnel and Development.

Broderick, R., \& Boudreau, J. W. (1992). Human resource management, information technology, and the competitive edge. The Executive, 7-17. http://dx.doi.org/10.5465/AME.1992.4274391

Bryman, A. (2001). Social research methods. Oxford University Press.

Bussler, L., \& Davis, E. (2002). Information systems: The quiet revolution in human resource management. Journal of Computer Information Systems, 42, 17-20.

Chapman, D. S., \& Webster, J. (2003). The Use of Technologies in the Recruiting, Screening, and Selection Processes for Job Candidates. International Journal of Selection and Assessment, 11, 113-120. http://dx.doi.org/10.1111/1468-2389.00234

Cherns, A. (1987). Principles of sociotechnical design revisted. Human Relations, 40, 153-161. DOI: http://dx.doi.org/10.1177/001872678704000303

Chien, C. F., \& Chen, L. F. (2008). Data mining to improve personnel selection and enhance human capital: A case study in high-technology industry. Expert Systems with Applications, 34, 280-290. http://dx.doi.org/10.1016/j.eswa.2006.09.003

Ciborra, C. (2002). The labyrinths of information: Challenging the wisdom of systems, Oxford University Press, USA.

Ciborra, C. (2004). The labyrinths of information: challenging the wisdom of systems, Oxford University Press.

CIPD. (2003). HR Survey: Where We Are, Where We're Heading. In CIPD (ed.). London.

Clegg, C. W. (2000). Sociotechnical principles for system design. Applied ergonomics, 31, 463-477. http://dx.doi.org/10.1016/S0003-6870(00)00009-0

Desanctis, G. (1986). Human Resource Information Systems: A Current Assessment. MIS quarterly, 10, 15-27.

Ein-Dor, P., \& Segev, E. (1978). Organizational Context and the Success of Management Information Systems. Management Science, 24, 1064-1077. http://dx.doi.org/10.1287/mnsc.24.10.1064

Evans, P., Pucik, V., \& Barsoux, J. L. (2006). The Global Challenge: Frameworks for International Human Resource Management. Mcgraw-Hill Publ.Comp.

Gamage, A. (2007). Impact of HRD Practices on Business Performance: An empirical analysis of manufacturing SMEs in Japan.

Gattiker, U. E. (1995). Firm and taxpayer returns from training of semiskilled employees. Academy of management Journal, 1152-1173. http://dx.doi.org/10.2307/256624

Haines, V. Y. \& Petit, A. (1997). Conditions for successful human resource information systems. Human Resource Management, 36, 261-275. http://dx.doi.org/10.1002/(SICI)1099-050X(199722)36:2<261::AID-HRM7>3.0.CO;2-V

Hatch, N. W., \& Dyer, J. H. (2004). Human capital and learning as a source of sustainable competitive advantage. Strategic management journal, 25, 1155-1178. http://dx.doi.org/10.1002/smj.421

Heidegger, M. (1977). The question concerning technology, and other essays, Garland Pub.

Hennessey Jr, H. (1979). Computer applications in human resource information systems. Human Resource Planning, 2, 205-213.

Hussain, Z., Wallace, J. \& Cornelius, N. E. 2007. The use and impact of human resource information systems on human resource management professionals. Information \& Management, 44, 74-89. http://dx.doi.org/10.1016/j.im.2006.10.006

Jackson, S., \& Philip, G. (2005). Organisational culture and the management of technological change.

Kavanagh, M. J., Johnson, R. D. \& Thite, M. (2011). Human Resource Information Systems: Basics, Applications, and Future Directions. SAGE Publications.

Kennedy, M. (2006). Talent Management: developing or preventing knowledge and capability? Strategies, 4.

Kwon, T. K. \& Zmud, R. W. (1987). Unifying the Fragmented Models of Information Systems Implementation. In Hirschheim, R. J. B. J. A. R. A. (Ed.) Critical Issues in Information Systems Research. New York: John 
Wiley and Sons.

Lewin, K. (1952). Group Decision and Social Change. In: NEWCOMBE, E. \& HARLEY, R. (Eds.) Readings in Social Psychology. New York: Henry Holt.

Luna-Reyes, L. F., Zhang, J., Gil-García, J. R., \& Cresswell, A. M. (2005). Information systems development as emergent socio-technical change: a practice approach. European journal of information systems, 14, 93-105. http://dx.doi.org/10.1057/palgrave.ejis.3000524

Martin, G., Reddington, M., \& Alexander, H. (2008). Technology, Outsourcing and Transforming HR, Butterworth-Heinemann.

Martinsons, M. G. (1994). Benchmarking human resource information systems in Canada and Hong Kong. Information \& Management, 26, 305-316. http://dx.doi.org/10.1016/0378-7206(94)90028-0

Mayo, A. (2004). Creating a Learning and Development Strategy: The HR Business Partner's Guide to Developing People, Chartered Institute of Personnel and Development.

Morse, J. M. (1994). Designing funded qualitative research. Handbook of qualitative research, 2, 220-235.

Myers, M. D. (2008). Qualitative Research in Business \& Management. Sage.

Ofek, E., \& Sarvary, M. (2001). Leveraging the customer base: Creating competitive advantage through knowledge management. Review of Marketing Science WP No. 315. http://dx.doi.org/10.1287/mnsc.47.11.1441.10249

Orlikowski \& Baroudi (1991). Studying Information Technology in Organizations: Research Approaches and Assumptions. Information Systems Research, 2, 1-28. http://dx.doi.org/10.1287/isre.2.1.1

Orlikowski, W., \& Hoffman, D. (1997). An Imporvisational Model for Change Managment: The Case of Groupware Technologies. Sloan Management Review, 38, 11-21.

Richards-Carpenter, C. (1982). Computers in personnel-New needs, new methods, new opportunities. Personnel Management, 14, 26-30.

Scapens, R. W. (1990). Researching management accounting practice: The role of case study methods. The British Accounting Review, 22, 259-281. http://dx.doi.org/10.1016/0890-8389(90)90008-6

Shrivastava, S. \& Shaw, J. B. (2003). Liberating HR through technology. Human Resource Management, 42, 201-222. http://dx.doi.org/10.1002/hrm.10081

Snell, S., Stuebner, D. \& Lepak, D. (2002). Virtual HR departments: Getting out of the middle. In Henneman, D. (Ed.), Human Resource Management in Virtual Organisations.

Walsham, G. (1995). Interpretive case studies in IS research: nature and method. European journal of information systems, 4, 74-81. http://dx.doi.org/10.1057/ejis.1995.9

Wright, P. M., Mcmahan, G. C., \& Mcwilliams, A. (1994). Human resources and sustained competitive advantage: a resource-based perspective. International Journal of Human Resource Management, 5, 301-326. http://dx.doi.org/10.1080/09585199400000020

\section{Copyrights}

Copyright for this article is retained by the author(s), with first publication rights granted to the journal.

This is an open-access article distributed under the terms and conditions of the Creative Commons Attribution license (http://creativecommons.org/licenses/by/3.0/). 